\title{
Adapting Evidence-Based Tobacco Addiction Treatment for Inuit Living in Ontario: A Qualitative Study of Collaboration and Co-creation to Move From Pan-Indigenous to Inuit-Specific Programming
}

\author{
Megan Barker, Anita Uuttuvak, Christine Lund, Rosa Dragonetti, Peter Selby
}

\section{A R T I C L E IN F O}

\author{
Keywords: \\ Indigenous \\ Inuit \\ Canada \\ Community-based participatory research \\ Tobacco cessation \\ Co-creation \\ Two-Eyed Seeing \\ Knowledge translation
}

https://doi.org/10.32799/ijih.v16i2.33119

\begin{abstract}
A B S T R A C T
Settler introduction of tobacco to Inuit Nunangat (homeland of Inuit in Canada) has led to high tobacco use prevalence among Inuit. Inuit are moving from traditional territories to the province of Ontario to access resources, including health services. Indigenous-specific tobacco cessation approaches in Ontario lack cultural relevance among Inuit, as they often reflect First Nations and Métis worldviews. To improve effectiveness of tobacco cessation services for Inuit living in Ontario, materials reflective of Inuit culture and worldviews were developed through a community-based participatory approach. The Centre for Addiction and Mental Health collaborated with Tungasuvvingat Inuit and members of an Engagement Circle who work with Inuit or identify as Inuk $(\mathrm{n}=$ 25 ) to initiate a knowledge translation project aimed at co-creating a toolkit of Inuit-specific cessation resources. Development was guided by Two-Eyed Seeing, whereby Inuit and Western worldviews come together to support a strengths-based approach. The toolkit was evaluated through a pilot session and focus group with Inuit living in Ottawa who use tobacco $(n=13)$ and an online survey administered with a group of helpers who work with Inuit $(n=11)$. Analysis of qualitative data from the focus group and online survey highlighted five themes: choice, cultural relevance and safety, capacity-building, access, and impact. Focus group participants reported they learned quitting was possible and identified new strategies to quit through the session. Our findings emphasize the importance of engagement and co-creation with Indigenous Peoples to ensure cultural relevance and appropriateness of healthcare interventions.
\end{abstract}

A U THOR IN F O

Megan Barker, MA, PhD candidate, Nicotine Dependence Service, Centre for Addiction and Mental Health, Toronto, Ontario, Canada; Dalla Lana School of Public Health, University of Toronto, Ontario, Canada.

Anita Uuttuvak, HBA, BA, Tungasuvvingat Inuit, Ottawa, Ontario, Canada

Christine Lund, Tungasuvvingat Inuit

Rosa Dragonetti, MSc, RP, Nicotine Dependence Service, Centre for Addiction and Mental Health; Department of Family and Community Medicine, University of Toronto 
Peter Selby, MBBS, CCFP(AM), FCFP, MHSc, DipABAM, DFASAM, Nicotine Dependence Service, Centre for Addiction and Mental Health; Department of Family and Community Medicine, Department of Psychiatry, and Dalla Lana School of Public Health, University of Toronto, Ontario, Canada. Email: peter.selby@camh.ca

\section{Acknowledgements}

This project was successfully completed through a partnership between the Centre for Addiction and Mental Health (CAMH) in Toronto and Tungasuvvingat Inuit (TI) in Ottawa, Ontario. CAMH and TI are grateful for the collaborative efforts of the Engagement Circle who generously shared their time, experience, and wisdom throughout the duration of the project. We would also like to extend our gratitude to our partners at Cancer Care Ontario's Indigenous Tobacco Program, CAMH's Shkaabe Makwa, and the Canadian Partnership Against Cancer for their support in convening the Engagement Circle, participation in this initiative, and ongoing guidance. We would also like to thank the helpers and Inuit living in Ottawa who took the time to share their thoughts regarding the toolkit and its activities. Their willingness to provide open and honest feedback has helped to develop a resource that will support Inuit through their tobacco cessation journeys. Finally, we would like to thank the bhasin consulting inc. Fund for Inclusion in Mental Health for their generous funding support that made the toolkit development, piloting, and evaluation possible.

\section{Glossary}

Inuit Nunangat: four regions across northern Canada that make up the homeland of the Inuit and include Nunatsiavut, Nunavik, Nunavut, and Inuvialuit

Inuit Qaujimajatuqangit (IQ) principles: a system of societal values, beliefs, and ways of knowing among Inuit. Although the term Inuit Qaujimajatuqangit is Nunavut-specific, the essence of the principles is recognized as being consistent with Inuit values and ways of knowing across Inuit Nunangat (Tagalik, 2009)

Inuktut: collective term for different spoken dialects or variations of Inuit languages including Inuktitut, Inuinnaqtun, and more

\section{Introduction}

Tobacco use prevalence among Inuit is more than triple that of the general Canadian population (Wallace, 2014). Inuit experience higher rates of tobacco-related disease and illnesses including tuberculosis (N'Diaye et al., 2019), cancer (Young et al., 2016), and premature death (Peters, 2013). Unlike many First Nations and Métis people who recognize tobacco as a sacred medicine (Michell, 1999), Inuit do not share the same cultural relationship with tobacco. The tobacco plant is unable to grow in the harsh Arctic climate and thus was never part of the traditional environment in which Inuit lived. Tobacco was first introduced to Inuit by explorers, whalers, traders, then settlers and used as currency in trading of Inuit furs and/or labour; however, it was only within the last 70 years that Inuit began to regularly use tobacco as it was increasingly made more available (Tobacco Has No Place Here, n.d.). This increase in tobacco 
use can be traced back to colonization. Destructive colonialist practices stripped Inuit of their traditional ways of knowing, nomadic way of life, families, and independence (Bjerregaard, 2001; Gracey \& King, 2009). Inuit that remain continue to experience effects of intergenerational trauma, with many using tobacco to cope.

Historically, health interventions for Indigenous Peoples have been developed without consultation or collaboration with community members. Western assumptions about what works to optimize health are also fraught with distorted notions about Indigenous cultural and spiritual healing practices (Schnarch, 2004). Additionally, health interventions are often developed with a pan-Indigenous approach, resulting in programs not always reflective of diverse cultural practices, values, sociohistorical context, and geographic considerations unique to each group (Health Council of Canada, 2010). The province of Ontario is the traditional land for many First Nations and Métis people; therefore, Indigenous-specific cessation interventions available in Ontario are reflective of First Nations and Métis cultural practices. However, Inuit are moving to Ontario, frequently to urban centres such as Ottawa and Toronto, to seek employment, health services, education, and so on (Patrick \& Tomiak, 2008). Accordingly, Inuit-specific cessation resources need to be developed to support individuals working with the growing Ontario Inuit community (healthcare providers, community health workers, prenatal workers, educators, etc., collectively known as "helpers") to address high prevalence of tobacco use.

This paper outlines the process of collaborative engagement to co-create a culturally relevant and safe toolkit for tobacco addiction treatment reflective of Inuit traditional ways of learning, knowing, healing, and recovery. We describe steps of co-creation, including information gathering and initial adaptation, testing, and modification (Barrera et al., 2013), using a participatory research approach. The paper will share findings from the helpers' review of the toolkit and pilot session of materials with Inuit living in Ottawa to demonstrate feasibility and potential for uptake. We also recommend improvements for tobacco addiction treatment with Inuit living in Ontario and beyond.

\section{Background}

In 2010, the Training Enhancement in Applied Counselling and Health (TEACH) Project, a knowledge translation project at the Centre for Addiction and Mental Health (CAMH), partnered with Ontario First Nations stakeholders, Elders, helpers, and community members to develop a commercial tobacco cessation toolkit to support helpers working with First Nations communities. Upon launching the toolkit, TEACH received multiple training requests to offer train-the-trainer sessions on toolkit materials from organizations providing services to First Nations, Inuit, and Métis. Feedback from the train-the-trainer sessions challenged the lack of diversity of teachings and cultural practices in the toolkit.

In March 2016, in collaboration with Cancer Care Ontario's Indigenous Tobacco Program, CAMH's Aboriginal Engagement and Outreach Program (now Shkaabe Makwa), and the Canadian Partnership Against Cancer, TEACH sent an invitation nationally to First Nations, Inuit, and Métis stakeholders, helpers, community members, and Elders to participate in the review of the toolkit. A new Engagement Circle was formed with 56 individuals representing 
multiple provinces and territories. Engagement Circle members were provided with three opportunities to offer their feedback, including a face-to-face meeting in Toronto, Ontario; a toolkit train-the-trainer session held in Happy Valley-Goose Bay, Labrador; and through structured reviews submitted electronically. This was to ensure an open and inclusive process. A key piece of feedback from the Engagement Circle was that toolkit activities and teachings were not relevant to Inuit Ways of Knowing. The Engagement Circle came to a consensus that the development of a separate toolkit for Inuit was required to increase their participation in culturally relevant tobacco cessation or reduction activities.

\section{Relationship}

TEACH partnered with Tungasuvvingat Inuit (TI), an Ontario-based Inuit-specific provincial service provider, and members of the previous Engagement Circle (formed in March 2016) who identified as Inuk or worked directly with Inuit and were representative of Inuit Nunangat $(n=25)$ to co-create a comprehensive toolkit of Inuit-specific cessation resources. High standards of ethical practice and cultural relevance were upheld through a communitybased participatory research approach, involving principles of community capacity, empowerment and critical consciousness, participation and relevance, and recognition of health inequities (Wallerstein et al., 2015). This approach has been shown to be successful in decolonizing the research process (Tobias et al., 2013) and can promote meaningful and collaborative engagement. Forming a partnership that equitably involves Inuit community members in all aspects of a project ensures that community priorities are addressed and that community well-being is paramount (Walters et al., 2009).

Prior to developing the toolkit of Inuit-specific tobacco cessation materials, a research protocol and data collection tool were developed and submitted to CAMH's Research Ethics Board for review and approval. The research protocol incorporated Inuit perspectives of research ethics informed by guiding documents (Inuit Tapiriit Kanatami \& Nunavut Research Institute, 2006; Nickels \& Knotsch, 2011). TEACH and TI also co-created and executed a partnership agreement to ensure Inuit perspectives were incorporated in the research process and roles and responsibilities were clearly outlined. Engagement Circle members were notified about the project and were invited to share interest in participation, discuss roles, and outline levels of contribution. Throughout the duration of the project, Engagement Circle members received monthly email updates regarding project developments and milestones.

\section{Toolkit Development}

\section{Methods}

TEACH and TI worked collaboratively to develop the initial toolkit outline. This outline was informed by guidance, knowledge, review, and consensus-building relating to the March 2016 Engagement Circle's review of the previous toolkit. Their suggestions for activities, content, and format were essential to ensuring a useful and relevant resource for use with Inuit looking to quit or reduce tobacco use. The outline was also informed by the guiding principle of 
Two-Eyed Seeing, conceptualized by Mi'kmaq Elders Albert and Murdena Marshall, which asks that we learn to see strengths of evidence-based practice with one eye (Western knowledge), and strengths of wise-based practice from the other eye (Indigenous Ways of Knowing). Taken together, we learn to use both eyes for the benefit of all (Marshall \& Marshall, 2012). Although Two-Eyed Seeing is derived from a Mi'kmaq worldview, the principle is inclusive and decolonizing, and it has been used to guide initiatives with many groups of Indigenous Peoples with diverse ways of knowing, including Inuit (Wright et al., 2019). The toolkit was informed by (a) evidence-based practice: Dermody et al.'s (2015) Group Cognitive Behavioural Therapy [CBT] for Smoking Cessation manual (implemented by the Nicotine Dependence Service at CAMH) and CAN-ADAPTT guidelines (2011); and (b) wise-based practice: Inuit Qaujimajatuqangit (IQ) principles (fundamental values and traditional ways of knowing among Inuit; Tagalik, 2009), teachings, and traditional activities to support healing and well-being. Combining these approaches can foster a strengths-based and wholistic approach to tobacco cessation or reduction. All CBT activities were culturally adapted through a lens of Inuit epistemology. For example, the readiness ruler — which asks clients to rate the importance of, or their confidence in, quitting tobacco use on a scale from 0 to 10 - was replaced with the visual of an Inuit drum (qilaujjaq) divided into four quadrants focusing on core areas of health (i.e., physical, mental, emotional, and spiritual).

Engagement Circle members reviewed the draft outline and identified gaps, recommended additional content, and indicated any issues within a 1-month period. Based on feedback and resources provided by the Engagement Circle, TEACH and TI developed the full toolkit over a 2-month period. The Engagement Circle reviewed a first draft of the toolkit and identified any modifications to content, additional resources to be included, and provided artwork or visuals for inclusion. This feedback was incorporated into a second draft of the toolkit.

The resulting Inuit-specific tobacco cessation toolkit, IT'S TIME (Indigenous Tools and Strategies on Tobacco: Interventions, Medicines, and Education), comprises four documents to support helpers in offering tobacco interventions with Inuit:

1. The Helper's Guide outlines six 90-minute sessions of Inuit-informed cognitive behavioural therapy.

2. The Helper's Condensed Guide includes summaries of key activities and discussion points to guide helpers in delivering sessions.

3. The Helper's Resources include supplementary material to support content and activities in the Helper's Guide.

4. The Participant Booklet includes information, handouts, and worksheets related to the content of each session to be shared with participants to support them on their tobacco cessation journeys.

Toolkit session content outlines the history of tobacco use in Inuit communities, connecting intergenerational trauma to tobacco use; explores what a cessation journey may look like; identifies triggers; and presents coping strategies - preparing for quitting, strategies for 
quitting, and ways to continue on the cessation journey once the sessions end. The toolkit is available for free download at https://www.nicotinedependenceclinic.com/en/teach/practitionerresources/teach-tool3.

\section{Pilot Session}

To assess cultural relevance of the toolkit materials, a pilot session with Inuit who use tobacco was held at TI in Ottawa, Ontario, in June 2017. Several Inuit service-providing agencies in Ottawa were engaged to recruit 13 Inuit living in Ottawa (18 or older, spoke and wrote English) to attend the pilot session. Participants attended the toolkit's first session, led by a settler-identifying registered nurse and an Indigenous health promoter, each with extensive experience in tobacco addiction treatment with Indigenous Peoples. Participants were provided with a copy of the participant booklet, which they used during activities and could bring home with them following the session. Lunch, snacks, and breaks were provided throughout the 90minute session.

\section{Data Collection and Analysis}

Immediately following the pilot session, an Inuk research analyst from TI and a settleridentifying research coordinator from TEACH led a 1-hour focus group. All pilot participants used a co-created discussion guide that included the following topics: participant's perception of the pilot session, initial impressions of content and activities, and whether the session made participants reflect on their own tobacco use. Participants were provided with honoraria for their time as well as a gift to acknowledge their willingness to share their knowledge. Reciprocity is a fundamental value among Indigenous Peoples and sharing knowledge is a precious gift (Absolon, 2010). The gift offered was a Bracelet of Strength handmade from deerskin in Curve Lake First Nation.

Participants were given time prior to the focus group to read the consent form and ask any questions. The research coordinator read the form aloud and gave participants additional time to sign the consent form. Participant feedback was audio recorded and transcribed verbatim. The research analyst and research coordinator reviewed the transcript together and developed a coding framework representative of both inductive and deductive themes that emerged. Data were then coded according to the framework independently and discussed together following completion of coding. Following analysis, participants who consented to participate in member checking interviews $(n=6)$ were contacted via telephone by the research coordinator to ensure accuracy, credibility, and validity of findings (Creswell \& Miller, 2000). The research coordinator read through each of the themes and associated interpretations and invited participants to confirm their accuracy. Participants agreed with interpretations and no new comments were provided.

In addition to the focus group, 11 helpers located across Canada who work with Inuit were recruited by the Engagement Circle to review the toolkit and provide feedback. Of these 11 helpers, nine submitted feedback through a 34-item online survey, and two provided in-depth reviews with editorial edits and suggestions for improvement. Open-ended responses provided 
by helpers in the survey and in-depth reviews were analyzed through the coding structure emerging from the focus group to "crystallize" the data (Tracy, 2010). Crystallization of data does not present a singular truth of an issue but can help to uncover a more complex and in-depth understanding of an issue (Tracy, 2010).

\section{Results}

Focus group participants and helpers shared similar opinions regarding the toolkit's content and materials. Through analysis of the focus group transcript and qualitative feedback provided by helpers in the online survey and in-depth reviews, five themes emerged: choice, cultural relevance and safety, capacity-building, access, and impact. These themes are explored in further depth below and relevant quotes have been provided and identified according to stakeholder group. Participants were given the choice to be identified by their given names, as is customary in research with historically marginalized groups who may wish to see their voice represented in study findings (van den Hoonaard, 2004). Participants who did not consent to this option chose a pseudonym, an established principle of good research practice (Allen \& Wiles, 2016).

\section{Choice}

A prominent theme that emerged in qualitative feedback from both focus group participants and helpers was the notion of choice as it related to concepts of tailoring, flexibility, and client-centredness. Helpers were impressed by the multitude of activities and resources helpers could choose from to tailor their approach to specific clients and/or their communities. Helpers reported that the ability to tailor content to a client or a community would increase access and usability of materials across a diversity of contexts (individual or group settings, remote or urban communities, etc.):

Great toolkit. Gives a great deal of options throughout the sessions to deal with different people that are willing to quit. (Travis, helper)

Helpers were also pleased the toolkit provided the flexibility needed for helpers to incorporate their own materials within sessions. They also mentioned that materials provided helpers with a diversity of supports to choose from to meet their needs as facilitators, including the condensed guide, prompts, objectives, and checklists for preparation:

Great job by all involved. I also like that there is flexibility for the communities to make it reflect who they are and able to work with the resources they have at hand. (Natalie, helper)

Helpers and focus group participants also identified suggestions for improvement to support the notion of choice through a client-centred context. Suggestions focused on increasing inclusivity to ensure participation among many clients regardless of where they were at in their

V OLUME 16 , IS S UE 2, $2021 \bullet 42$ 
tobacco cessation or reduction journey; and providing more opportunities to personalize activities to increase meaningfulness with each individual client:

When it lists the Inuit Qaujimajatuqangit, instead of just giving the information to people, maybe you can add another column in there and you can get the participants to list different examples of each principle in regards to tobacco use and how that ... know what I mean? Just to engage the participants and keep their attention, right? (Ulaaju, focus group participant)

\section{Cultural Relevance and Safety}

Helpers and focus group participants described ways in which the toolkit content and activities were culturally relevant and safe and also offered suggestions to enhance cultural relevance. A theme that emerged from qualitative feedback was the toolkit's alignment with IQ principles. Helpers liked the inclusion of IQ principles in the toolkit. Focus group participants were satisfied with the group format of the session as it is aligned with Inuit values:

Under activities ... so happy to see IQ list is physically being used and implemented in all areas of this tool. (Annie, helper)

Yeah, a group is all right. We come from a group. (David, focus group participant)

Helpers also commented on inclusion of both evidence- and wise-based practices to support a wholistic approach to tobacco cessation, a reflection of the toolkit's grounding in TwoEyed Seeing:

The program adaptation looks really good. I love how you adapted the medicine wheel into the Inuit drum. (Natalie, helper)

I thought it incorporated both the Western and Inuit-based interventions. (Alison, helper)

Helpers and focus group participants also provided suggestions for improvement to enhance cultural relevance and safety of the intervention and materials. These included offering activities to support Inuit living in Ottawa who may feel isolated or disconnected from their homes in the North, incorporating more visuals to promote immersion with materials, and including more traditional protocols:

Visual communication is always well received by Inuit. I would recommend incorporating pictures to convey information whenever possible. (Laura, helper)

Offer traditional food, and maybe have an Elder open and close. (Janice, focus group participant) 


\section{Capacity-Building}

Feedback indicated the need for capacity-building (i.e., training, building skills, and increasing awareness of harms associated with tobacco use) to support helpers in delivering toolkit materials and support clients in furthering their tobacco reduction or cessation journeys. In terms of helper support, a helper mentioned materials might not be used if helpers do not have adequate training to deliver content. Another helper recommended involving clients as cofacilitators in implementation of toolkit materials to support capacity-building from a client/community perspective, and to increase buy-in from fellow Inuit:

My only comment beyond editorial would be suggesting a co-facilitator or co-helper that is a peer or community member with lived experience (e.g., community member who has successfully quit smoking) might be helpful in these group settings. This takes just the right person-someone with the right skill/experience and training, but is a strategy used in other group addictions programs. It takes it a step beyond simply having an Elder or community member opening and closing the sessions, but also actively participating and facilitating all of the sessions. (Kristy, helper)

In terms of client support, focus group participants spoke about incorporating more discussion on coping strategies to promote quitting or reduction. They recommended providing opportunities to collaboratively identify strategies to support quitting in a group format. Additionally, focus group participants spoke at length about how sessions should incorporate more information on negative aspects of tobacco use to increase awareness regarding harms associated with continued use:

I think it's more about engaging the participants. If you guys are going to have this as a group rather than somebody finding the material online, to be more ... to engage the participants more instead of listing all the things I can do, coping strategies? Maybe you guys can just use that as a guideline and ask the participants what they do instead of ... just having it listed there, you know? (Ulaaju, focus group participant)

Even show a healthy lung and a bad lung, even what they try to do on the cigarette packet looks gross but you know what? If that will help someone think of quitting ... (Victoria, focus group participant)

\section{Access}

Helpers and focus group participants recommended ways to ensure equitable access of toolkit materials. A few helpers recommended the toolkit undergo a plain language review to promote accessibility of materials with helpers and clients who may have diverse literacy needs. Helpers also recommended a translation of materials to Inuktitut, one dialect of Inuktut: 
I would suggest having a reviewer who specializes in plain language. Some of the wording in the participant booklet (or even the helper booklet, depending on who is facilitating) may be a bit hard to understand for those with low literacy. Example from Coping Strategies in participant booklet: "Recognize when you are making self-defeating statements." This might need a clearer explanation and some examples. Even the word cessation is difficult for some to understand. (Laura, helper)

My only concern [is] for the individuals whose literacy may not be as strong or they don't read English well. Is there an Inuktitut version or would there be for the communities where the language is strong? (Natalie, helper)

Helpers recommended having materials available in multiple formats (e.g., electronic and hard copy), so helpers can easily play recommended videos offline, because access to free or reliable internet can be an issue in some remote communities. Helpers and focus group participants also recommended widespread dissemination (including word of mouth) to ensure relevant Inuit service-providing agencies have access:

Not everybody uses computers or social media and it's important to spread it through word of mouth, like through drop-in centres or ... because I went there this morning, and everybody was asking me where I found out, how I found out about this. And I said it was just through email alerts. But not everybody uses computers. (Ulaaju, focus group participant)

Focus group participants also encouraged helpers to offer incentives to attend sessions as a way to increase participation. Incentives discussed included food, money for transportation, gift cards, and items such as chewing gum to distract participants from smoking.

\section{Impact}

Focus group participants shared ways that participating in the session could impact their smoking and identified steps they would take to quit or reduce tobacco use. Participants reported that attending the session had changed their thinking regarding tobacco use; for example, they could better see how quitting was possible and how family could be a motivator to quitting. They also learned new strategies they said they would consider trying. Furthermore, participants mentioned attending the session was valuable because they heard relatable stories:

I like the program, because it shows that there's a better way to quit smoking than keep going. (Grace, focus group participant)

And what I liked about today's session was that ... I'm glad to hear that my nieces and nephews can be a motivational ... reason why to quit smoking. I really like that part. (Lucassie, focus group participant) 
You know you're not alone. (Kathy, focus group participant)

Focus group participants indicated they would take small steps to start the quitting process as a result of attending the session. They also mentioned specific tools in the participant booklet they would use following the session to be able to track their smoking and behaviours:

Bring just a certain amount of cigarettes with you to help you cut down. Instead of bringing your full pack, maybe you can bring five or six. (Ulaaju, focus group participant)

I'm going to try the tracking sheet. And after that, I'm going to stop drinking to quit smoking. (Akeesho, focus group participant)

\section{Discussion}

Through collaborative engagement and co-creation, a tobacco addiction treatment toolkit, IT'S TIME, reflective of both Western and Inuit Ways of Knowing, was developed, assessed, and evaluated. Feedback provided by focus group participants and helper reviewers supports collaboration and co-creation in developing tobacco cessation interventions to promote (a) clientcentred and responsive care to meet diverse community and individual needs; (b) culturally relevant and safe treatment approaches reflective of Inuit Ways of Knowing, healing, and recovery; (c) capacity-building opportunities to support helpers and clients within a treatment context; (d) equitable access to culturally relevant interventions; and (e) concrete changes to tobacco use (e.g., changing location of smoking or withholding cigarettes). The following discussion outlines ways to improve tobacco addiction treatment for Inuit.

Based on feedback provided by helpers and focus group participants, tobacco addiction treatment with Inuit needs to support choice at both a helper and a client level. Helpers require access to cessation materials broad enough for use with many clients, yet able to be modified and tailored to community context and meet diverse client needs. For example, some communities may prefer to incorporate evidence-based approaches to cessation, while others may prefer a wise-based approach. With ongoing effects of colonization, Inuit have historically lacked freedom to make choices, particularly when their health is involved (Brascoupé \& Waters, 2009). By providing a multitude of activities representative of Western and Inuit Ways of Knowing, helpers, along with their clients, have autonomy to choose preferred approaches that can support tobacco cessation and reduction outcomes.

Through colonization, traditional approaches to health and well-being came to be viewed as inferior and therefore neglected within Western healthcare. However, tobacco cessation programs that include ceremonial practices or culturally based activities report improved quit rates and overall improvements in health compared with Western approaches alone (Minichiello et al., 2015). Among Inuit, these activities may include carving, tattooing, storytelling, throat singing, drum and ulu making, hunting, and fishing. Helper and focus group participant feedback also highlighted the importance of culturally relevant and safe tobacco addiction treatment. 
Feedback confirmed a successful approach to aligning IQ principles in Inuit tobacco cessation. To achieve this, the toolkit was informed by a strengths-based approach, incorporating family and community within care. Additionally, all CBT activities included in the toolkit were culturally adapted to incorporate Inuit Ways of Knowing. Reimagining evidence-based approaches to tobacco cessation like CBT is one way to support tailored and culturally relevant treatment.

The toolkit also included land-based activities to support tobacco cessation or reduction (e.g., drying or stretching skins, making or fixing dog team equipment or sleds, making or fixing items required for hunting and fishing, reading the weather, hunting, fishing, collecting fresh ice water). Traditional knowledge among Inuit is firmly rooted in and transmitted through the land based on cumulative collective experience and testing over centuries by people with a deep and practical understanding of the land out of necessity for survival (Royal Commission on Aboriginal Peoples, 1996). Thus, incorporating land-based activities within tobacco cessation treatment can bring people back to traditional ways of knowing founded in promoting strengths and well-being. Feedback from project participants provide many tangible recommendations to enhance culturally relevant and safe tobacco cessation treatment, including offering traditional food, incorporating traditional protocols, involving an Elder in care, and incorporating visuals reflective of Inuit worldview. Helpers offering tobacco addiction treatment may consider these culturally relevant recommendations to inform their own cessation programming.

One key finding for capacity-building highlighted the need for increased support among helpers to deliver tobacco cessation treatment through appropriate training or co-facilitation with community members. This finding is consistent with the literature. Despite available information and guidelines to treat tobacco addiction, few helpers offer tobacco cessation treatment, citing lack of training and self-confidence (Deckter et al., 2009; Maynard et al., 2012; Vogt et al., 2005). Training helpers in tobacco addiction treatment has been shown to increase delivery of tobacco cessation interventions among helpers and improved quitting among clients (Carson et al., 2012). With regard to co-facilitation of tobacco cessation groups with community members, this finding aligns with group therapy literature, which indicates an increasing number of support groups led by peers. Individuals who have similar lived experiences can support tobacco cessation or reduction through increasing confidence, promoting well-being, and sharing knowledge about quitting (Ashton et al., 2015).

Another finding related to capacity-building was a need for tobacco use psychoeducation among Inuit. In particular, focus group participants recommended needing more information about harms associated with tobacco use to encourage reduction or cessation. In a study conducted by Gould and colleagues with Aboriginal and Torres Strait Islanders (2013), participants expressed significant gaps in knowledge as it related to harms associated with tobacco use. If they received messaging about harms associated with tobacco use, it appeared to be more significant if messaging was aligned with their own lived experience (Gould et al., 2013). Tailoring messages about tobacco harms for Inuit could increase knowledge and help with reduction or quitting. 
In 2011, 67\% of Inuit aged 20 to 24 years in Inuit Nunangat had less than a high school diploma (Statistics Canada, 2011), while $87 \%$ of the general Canadian population had obtained a high school diploma (Statistics Canada, 2016b). This inequitable demographic is reflected in helpers' recommendation that the toolkit undergo a plain language review to ensure accessibility of materials with a variety of helpers and clients. Helpers should be aware of the possibility of differing literacy levels among their Inuit clients, and provide services tailored to their clients' needs. Additionally, 56\% of Inuit across Inuit Nunangat speak Inuktitut (Statistics Canada, 2016a), so it was not surprising that helpers also recommended materials be translated from English to Inuktitut to expand reach and usability. This is aligned with the increasing number of Inuit organizations and governments encouraging use of Inuktitut at regional and national levels to ensure its protection and enhancement (Inuit Tapiriit Kanatami, 2014). However, translation to Inuktitut for a product developed for Inuit living in Ontario is complicated, as there are many dialects of Inuktut spoken across Inuit Nunangat. Inuit move to Ontario from each of the regions, so it is challenging to choose one dialect over the other. Future consultation with the Engagement Circle will help to guide a translation approach. In regards to other recommendations related to access, focus group participants suggested helpers offer incentives to attend programming to increase participation (e.g., food, money for transportation, gift cards, items to distract them from smoking during the group session). It has been well documented that providing incentives can increase likelihood of health behaviour change (Giles et al., 2014), particularly among populations that may not respond to "mainstream" tobacco cessation programming (Alessi \& Petry, 2014; Drummond et al., 2014; Higgins et al., 2012).

Feedback provided by focus group participants regarding session impact can support helpers' understanding of barriers and motivators for quitting or reducing tobacco use and preferred formats for programming among Inuit. Strong familial relationships are foundational to Inuit culture (Inuit Tapiriit Kanatami, 2014), so it is no surprise focus group participants mentioned family as an important motivator to quit or reduce tobacco use. Focus group participants were pleased the pilot session provided them with an opportunity to hear relatable stories. In communities where tobacco use is highly prevalent, having the opportunity to interact with individuals who are thinking about quitting or reducing may not be readily available (Bond et al., 2012). Individuals who are surrounded by others who use tobacco are far less likely to try quitting or reducing (Ivers et al., 2003). However, when individuals are connected with positive support systems to help reinforce quitting or reducing, they are more likely to adhere to treatment, quit smoking, and remain tobacco-free (Christakis \& Fowler, 2008; Park et al., 2004; Westmaas et al., 2010). To help promote quitting or reducing tobacco use, helpers should consider providing group therapy for tobacco cessation with Inuit so shared experiences can be safely expressed.

\section{Limitations}

Although this project involved an Engagement Circle who shared ideas for content and activities, reviewed drafts, and provided recommendations for resources, involving the 
Engagement Circle members in writing toolkit content would have ensured a true collaborative process. Unfortunately, due to time and financial constraints, content writing was completed largely by TEACH and TI, with the Engagement Circle providing an advisory role. Financial constraints also prevented the development of the toolkit in dialects of Inuktut, limiting involvement of Elders and Knowledge Keepers, whose voices may have impacted the toolkit design and delivery in unknown ways.

Prior to recruiting helpers to participate in toolkit review, it would have been helpful to convene an in-person meeting with the Engagement Circle to seek additional feedback. This may have led to more helpers reviewing the toolkit. Similarly, offering more time for review may have increased the participation of helpers who are often faced with competing priorities and time constraints. Finally, we had additional individuals who were interested in participating in the pilot session and focus group but who could not attend at the scheduled date and time. Offering more sessions at different times might have accommodated additional participants whose views might differ from those of the individuals who did participate.

\section{Conclusion}

Greater engagement with Inuit ensures cultural relevance and appropriateness of tobacco cessation interventions in design and implementation to improve outcomes. Findings from this project suggest collaboration and co-creation can support culturally adapted tobacco addiction treatment for Inuit that is client-centred and incorporates Inuit Ways of Knowing. Collaboration and co-creation methodology can be applied beyond tobacco addiction treatment to ensure culturally relevant interventions across a range of health behaviours, including other substance use, physical activity, nutrition, oral health, and mental health. This paper also provides groundwork for future research to explore utility of collaboration and co-creation in development of health interventions with other Indigenous Peoples. Future research with the IT'S TIME toolkit will include additional pilot sessions followed by widespread implementation and evaluation across Inuit Nunangat to assess relevance and effectiveness outside of Ontario. We are hopeful the IT'S TIME toolkit will improve helpers' ability to deliver Inuit-specific cessation treatment and lead to improved cessation outcomes among Inuit throughout Ontario and beyond.

\section{References}

Absolon, K. (2010). Indigenous wholistic theory: A knowledge set for practice. First Peoples Child \& Family Review, 5(2), 74-87. https://doi.org/10.7202/1068933ar

Alessi, S. M., \& Petry, N. M. (2014). Smoking reductions and increased self-efficacy in a randomized controlled trial of smoking abstinence: Contingent incentives in residential substance abuse treatment patients. Nicotine \& Tobacco Research, 16(11), 1436-1445. https://doi.org/10.1093/ntr/ntu095

Allen, R. E. S., \& Wiles, J. L. (2016). A rose by any other name: Participants choosing research pseudonyms. Qualitative Research in Psychology, 13(2), 149-165. https://doi.org/10.1080/14780887.2015.1133746 
Ashton, M., Rigby, A., \& Galletly, C. (2015). Evaluation of a community-based smoking cessation programme for people with severe mental illness. Tobacco Control, 24(3), 275280. http://doi.org/10.1136/tobaccocontrol-2013-051179

Barrera, M., Jr., Castro, F. G., Strycker, L. A., \& Toobert, D. J. (2013). Cultural adaptations of behavioral health interventions: A progress report. Journal of Consulting and Clinical Psychology, 81(2), 196-205. http://doi.org/10.1037/a0027085

Bjerregaard, P. (2001). Rapid socio-cultural change and health in the Arctic. International Journal of Circumpolar Health, 60(2), 102-111. https://europepmc.org/abstract/med/11507959

Bond, C., Brough, M., Spurling, G., \& Hayman, N. (2012). "It had to be my choice": Indigenous smoking cessation and negotiations of risk, resistance and resilience. Health, Risk \& Society, 14(6), 565-581. https://doi.org/10.1080/13698575.2012.701274

Brascoupé, S., \& Waters, C. (2009). Cultural safety: Exploring the applicability of the concept of cultural safety to Aboriginal health and community wellness. Journal of Aboriginal Health [now International Journal of Indigenous Health], 5(2), 6-41. https://doi.org/10.3138/ijih.v5i2

CAN-ADAPTT: Canadian Action Network for the Advancement, Dissemination and Adoption of Practice-Informed Tobacco Treatment. (2011). Canadian smoking cessation clinical practice guideline. https://www.nicotinedependenceclinic.com/en/canadaptt/PublishingImages/Pages/CANADAPTT-Guidelines/CANADAPTT\%20Canadian\%20Smoking\%20Cessation\%20Guideline_website.pdf

Carson, K. V., Verbiest, M. E. A., Crone, M. R., Brinn, M. P., Esterman, A. J., Assendelft, W. J. J., \& Smith, B. J. (2012). Training health professionals in smoking cessation. Cochrane Database of Systematic Reviews, 5, Article CD000214. https://doi.org/10.1002/14651858.CD000214.pub2

Christakis, N. A., \& Fowler, J. H. (2008). The collective dynamics of smoking in a large social network. New England Journal of Medicine, 358(21), 2249-2258. https://doi.org/10.1056/NEJMsa0706154

Creswell, J. W., \& Miller, D. L. (2000). Determining validity in qualitative inquiry. Theory Into Practice, 39(3), 124-130. https://doi.org/10.1207/s15430421tip3903_2

Deckter, L., Mahabee-Gittens, E. M., \& Gordon, J. S. (2009). Are pediatric ED nurses delivering tobacco cessation advice to parents? Journal of Emergency Nursing, 35(5), 402-405. https://doi.org/10.1016/j.jen.2007.10.018

Dermody, S., Wardell, J., \& Hendershot, C. (2015). Group cognitive behavioural therapy for smoking cessation. Centre for Addiction and Mental Health.

Drummond, M. B., Astemborski, J., Lambert, A. A., Goldberg, S., Stitzer, M. L., Merlo, C. A., Rand, C. S., Wise, R. A., \& Kirk, G. D. (2014). A randomized study of contingency management and spirometric lung age for motivating smoking cessation among injection drug users. BMC Public Health, 14(1), Article 761. https://bmcpublichealth.biomedcentral.com/articles/10.1186/1471-2458-14-761 
Giles, E. L., Robalino, S., McColl, E., Sniehotta, F. F., \& Adams, J. (2014). The effectiveness of financial incentives for health behaviour change: Systematic review and meta-analysis. PloS One, 9(3), Article e90347. https://doi.org/10.1371/journal.pone.0090347

Gould, G. S., Munn, J., Avuri, S., Hoff, S., Cadet-James, Y., McEwen, A., \& Clough, A. R. (2013). "Nobody smokes in the house if there's a new baby in it": Aboriginal perspectives on tobacco smoking in pregnancy and in the household in regional NSW Australia. Women and Birth, 26(4), 246-253. https://doi.org/10.1016/j.wombi.2013.08.006

Gracey, M., \& King, M. (2009). Indigenous health part 1: Determinants and disease patterns. The Lancet, 374(9683), 65-75. https://doi.org/10.1016/S0140-6736(09)60914-4

Health Council of Canada. (2010). Health Council of Canada update: Improving the health and well-being of Aboriginal Peoples in Canada. https://healthcouncilcanada.ca/files/2.02AboriginalHealthUpdate_E_Oct252010.pdf

Higgins, S. T., Washio, Y., Heil, S. H., Solomon, L. J., Gaalema, D. E., Higgins, T. M., \& Bernstein, I. M. (2012). Financial incentives for smoking cessation among pregnant and newly postpartum women. Preventive Medicine, 55(Suppl.), S33-S40. https://doi.org/10.1016/j.ypmed.2011.12.016

Inuit Tapiriit Kanatami. (2014). Social determinants of Inuit health in Canada. https://www.itk.ca/wp-content/uploads/2016/07/ITK_Social_Determinants_Report.pdf

Inuit Tapiriit Kanatami and Nunavut Research Institute. (2006). Negotiating research relationships with Inuit communities: A guide for researchers. https://www.nri.nu.ca/sites/default/files/public/files/06068\%20ITK\%20NRR\%20booklet.pdf

Ivers, R. G., Farrington, M., Burns, C. B., Bailie, R. S., D’Abbs, P. H., Richmond, R. L., \& Tipiloura, E. (2003). A study of the use of free nicotine patches by Indigenous people. Australian and New Zealand Journal of Public Health, 27(5), 486-490. https://doi.org/10.1111/j.1467-842X.2003.tb00819.x

Marshall, M., \& Marshall, A. (2012, February 13-17). Two-Eyed Seeing Etuaptmumk: Mi'kmaw traditional knowledge [Presentation for Chapleau First Nation]. Retrieved from Institute for Integrative Science \& Health website: http://www.integrativescience.ca/uploads/articles/2012Feb-Marshall-Two-Eyed-SeeingChapleau-First-Nation.pdf

Maynard, A., Metcalf, M., \& Hance, L. (2012). Enhancing readiness of health profession students to address tobacco cessation with patients through online training. International Journal of Medical Education, 3, 57-62. https://doi.org/10.5116/ijme.4f70.bd8b

Michell, H. (1999). Pakitinasowin: Tobacco offerings in exchange for stories and the ethic of reciprocity in First Nations research. Journal of Indigenous Thought. Saskatchewan Indian Federated College [now First Nations University of Canada], Department of Indian Studies.

Minichiello, A., Lefkowitz, A. R. F., Firestone, M., Smylie, J. K., \& Schwartz, R. (2015). Effective strategies to reduce commercial tobacco use in Indigenous communities 
globally: A systematic review. BMC Public Health, 16(1), Article 21.

https://bmcpublichealth.biomedcentral.com/articles/10.1186/s12889-015-2645-X

N'Diaye, D. S., Nsengiyumva, N. P., Uppal, A., Oxlade, O., Alvarez, G. G., \& Schwartzman, K. (2019). The potential impact and cost-effectiveness of tobacco reduction strategies for tuberculosis prevention in Canadian Inuit communities. BMC Medicine, 17(1), Article 26. https://bmcmedicine.biomedcentral.com/articles/10.1186/s12916-019-1261-5

Nickels, S., \& Knotsch, C. (2011). Inuit perspectives on research ethics: The work of Inuit Nipingit. Études/Inuit/Studies, 35(1-2), 57-81. https://doi.org/10.7202/1012835ar

Park, E.-W., Tudiver, F., Schultz, J. K., \& Campbell, T. (2004). Does enhancing partner support and interaction improve smoking cessation? A meta-analysis. Annals of Family Medicine, 2(2), 170-174. https://doi.org/10.1370/afm.64

Patrick, D., \& Tomiak, J.-A. (2008). Language, culture and community among urban Inuit in Ottawa. Études/Inuit/Studies, 32(1), 55-72. https://doi.org/10.7202/029819ar

Peters, P. A. (2013). An age- and cause-decomposition of differences in life expectancy between residents of Inuit Nunangat and residents of the rest of Canada, 1989 to 2008. Health Reports, 24(12), 3-9. https://www150.statcan.gc.ca/n1/pub/82-003x/2013012/article/11890-eng.pdf

Royal Commission on Aboriginal Peoples. (1996). Report of the Royal Commission on Aboriginal Peoples: Vol. 4. Perspectives and realities. http://data2.archives.ca/e/e448/e011188230-04.pdf

Schnarch, B. (2004). Ownership, control, access, and possession (OCAP) or self-determination applied to research: A critical analysis of contemporary First Nations research and some options for First Nations communities. Journal of Aboriginal Health [now International Journal of Indigenous Health], 1(1), 80-95. https://doi.org/10.3138/ijih.v1i1.28934

Statistics Canada. (2011). 2011 National Household Survey: Data tables [Catalogue no. 99-012X2011045]. https://www12.statcan.gc.ca/nhs-enm/2011/dp-pd/dt-td/Apeng.cfm?LANG $=\mathrm{E} \& A P A T H=3 \& D E T A I L=0 \& D I M=0 \& F L=A \& F R E E=0 \& G C=0 \& \mathrm{GID}=$ $0 \& \mathrm{GK}=0 \& \mathrm{GRP}=0 \& \mathrm{PID}=106201 \& \mathrm{PRID}=0 \& \mathrm{PTYPE}=105277 \& \mathrm{~S}=0 \& \mathrm{SHOW} A L L=1 \& \mathrm{~S}$ $\mathrm{UB}=0 \&$ Temporal $=2013 \& \mathrm{THEME}=96 \& \mathrm{VID}=0 \& \mathrm{VNAMEE}=\& \mathrm{VNAMEF}=$

Statistics Canada. (2016a). Data tables, 2016 census [Catalogue no. 98-400-X2016159]. https://www12.statcan.gc.ca/census-recensement/2016/dp-pd/dt-td/index-eng.cfm.

Statistics Canada. (2016b). High school graduates [Data set, Catalogue no. 82-229-X3009001]. http://www.statcan.gc.ca/pub/82-229-x/2009001/envir/hsg-eng.htm

Tagalik, S. (2009). Inuit Qaujimajatuqangit: The role of Indigenous knowledge in supporting wellness in Inuit communities in Nunavut. National Collaborating Centre for Aboriginal Health. https://www.nccih.ca/docs/health/FS-InuitQaujimajatuqangitWellnessNunavutTagalik-EN.pdf

Tobacco Has No Place Here. (n.d.). Tobacco was never part of Inuit culture. http://www.nuquits.gov.nu.ca/tobacco-101

Tobias, J. K., Richmond, C. A. M., \& Luginaah, I. (2013). Community-based participatory research (CBPR) with Indigenous communities: Producing respectful and reciprocal 
research. Journal of Empirical Research on Human Research Ethics, 8(2), 129-140. https://doi.org/10.1525/jer.2013.8.2.129

Tracy, S. J. (2010). Qualitative quality: Eight "big-tent" criteria for excellent qualitative research. Qualitative Inquiry, 16(10), 837-851. https://doi.org/10.1177/1077800410383121

van den Hoonaard, W. C. (2004). Fostering human dignity: Some inherent ethical dimensions of qualitative research. In J. Fik Fak, F. Adam, \& D. Garz (Eds.), Qualitative research: Different perspectives - emerging trends (pp. 265-279). ZRC Publishing.

Vogt, F., Hall, S., \& Marteau, T. M. (2005). General practitioners' and family physicians' negative beliefs and attitudes towards discussing smoking cessation with patients: A systematic review. Addiction, 100(10), 1423-1431. https://doi.org/10.1111/j.13600443.2005.01221.x

Wallace, S. (2014). Inuit health: Selected findings from the 2012 Aboriginal Peoples Survey [Data set, Catalogue no. 89-653-X, no. 003]. Statistics Canada. http://www.statcan.gc.ca/pub/89-653-x/89-653-x2014003-eng.htm

Wallerstein, N., Minkler, M., Carter-Edwards, L., Avila, M., \& Sánchez, V. (2015). Improving health through community engagement, community organization, and community building. In K. Glanz, B. K. Rimer, \& K. Viswanath (Eds.), Health behavior: Theory, research, and practice (5th ed., pp. 277-300). Jossey-Bass.

Walters, K. L., Stately, A., Evans-Campbell, T., Simoni, J. M., Duran, B., Schultz, K., Stanley, E. C., Charles, C., \& Guerrero, D. (2009). "Indigenist" collaborative research efforts in Native American communities. In A. Rubin Stiffman (Ed.), The field research survival guide (pp. 146-173). Oxford University Press. https://doi.org/10.1093/acprof:oso/9780195325522.003.0008

Westmaas, J. L., Bontemps-Jones, J., \& Bauer, J. E. (2010). Social support in smoking cessation: Reconciling theory and evidence. Nicotine \& Tobacco Research, 12(7), 695-707. https://doi.org/10.1093/ntr/ntq077

Wright, A. L., Gabel, C., Ballantyne, M., Jack, S. M., \& Wahoush, O. (2019). Using Two-Eyed Seeing in research with Indigenous people: An integrative review. International Journal of Qualitative Methods, 18. https://doi.org/10.1177/1609406919869695

Young, T. K., Kelly, J. J., Friborg, J., Soininen, L., \& Wong, K. O. (2016). Cancer among circumpolar populations: An emerging public health concern. International Journal of Circumpolar Health, 75(1), Article 29787. https://doi.org/10.3402/ijch.v75.29787 